\title{
Research on the Internal Influencing Mechanism of Patent Conversion in National Scientific Research Institutions
}

\author{
Xie Xuemei, Qi Ruiqian \\ Beijing University of Posts and Telecommunications \\ Beijing, China \\ E-mail:xxuem@163.com,ruiqianqi@163.com
}

\begin{abstract}
This paper conducts a research about the patent conversion of national scientific research institutions. The objective is to find out the main influencing factors for the patent formation period, and study the relationship among various factors. The research constructs an internal influencing mechanism model for patent conversion, and then conducts an empirical analysis and verification of assumption relationship of models through AMOS statistical software, to reveal the internal mechanism of the scientific research ability of national scientific research institution, the conversion intention of scientific research personnel, and the system satisfaction for patent conversion characteristics during the patent formation period. The result shows the following points: the external conversion characteristics of the patent for national scientific research institutions are realized through the internal conversion characteristics, and the internal conversion characteristics are directly influenced by the scientific research capacity and conversion intention; the scientific research capacity and conversion intention have bidirectional promotion function; the system satisfaction has a moderating effect on the model. Compared with scientific research capacity, the conversion intention has more influence on the external conversion characteristics of patent. Therefore, national scientific research institutions should emphasize on promoting the conversion intention of scientific research personnel to improve the external characteristics of patent conversion to a larger extent.
\end{abstract}

Keywords-Scientific research institutions; Patent conversion; Influencing mechanism; Moderator variable

\section{INTRODUCTION}

In 2016, the implementation rate for effective invention patent in China was $67.8 \%$, of which the rate for colleges and scientific research institutions was respectively $16.2 \%$ and $29.2 \%$; the industrialization rate for effective invention patent was $36.7 \%$, of which the rate for colleges and scientific research institutions was respectively $5.1 \%$ and $14.4 \%$ [1]. The application of invention patents in colleges and scientific research institutions were far lower than the average level.

In order to further improve the capacity of Chinese colleges and scientific research institutions for converting science and technology into actual productivity, relevant scholars have conducted lots of research. As can be seen from the research object, it is mainly focused on the conversion of scientific and technological achievements, and there are few researches focused on patent conversion [2-9]; from the research contents, it is mainly focused on the analysis of influencing factors in the patent conversion process [3-5], the construction of evaluation system [4-6] and the conversion mode [7-8]. There are few researches focused on the action mechanism of patent in the conversion process.

Patent conversion can be divided into the formation period, commercial period and industrialization period [9]. The conversion characteristics of patent are the key to future conversion, which have been confirmed during the formation period. This paper regards colleges and scientific research institutions as the main representatives for national scientific research institutions, and then pointedly analyzes the influencing factors of patent conversion in the formation period, constructs internal influencing mechanism model, explains the route and mode for the influencing factors to influence the patent conversion characteristics and provides support suggestions for improving the patent conversion capacity of national scientific research institutions.

\section{RESEARCH DESIGN}

\section{A. Hypothesis Model}

The conversion characteristics of patent are the basis whether patent conversion can be successfully conducted. As for patent, with the internal conversion characteristics such as advanced technology, high maturity, good unsubstitutability, the expression of market incomes, competitiveness, industrial development and other external conversion characteristics is more superior, and can easily implement conversion. Thus, assumption is put forward as follows:

H1: the internal conversion characteristics of patent have positive relativity with the external conversion characteristics.

$\mathrm{H} 2$ : the scientific research capacity has positive relativity with the internal conversion characteristics.

$\mathrm{H} 3$ : the conversion intention has positive relativity with the internal conversion characteristics. 
$\mathrm{H} 4$ : the conversion intention has positive relativity with the external conversion characteristics.

H5: the scientific research capacity and the conversion intention are bi-directionally related.

H6: the system satisfaction has a moderating effect on the model.

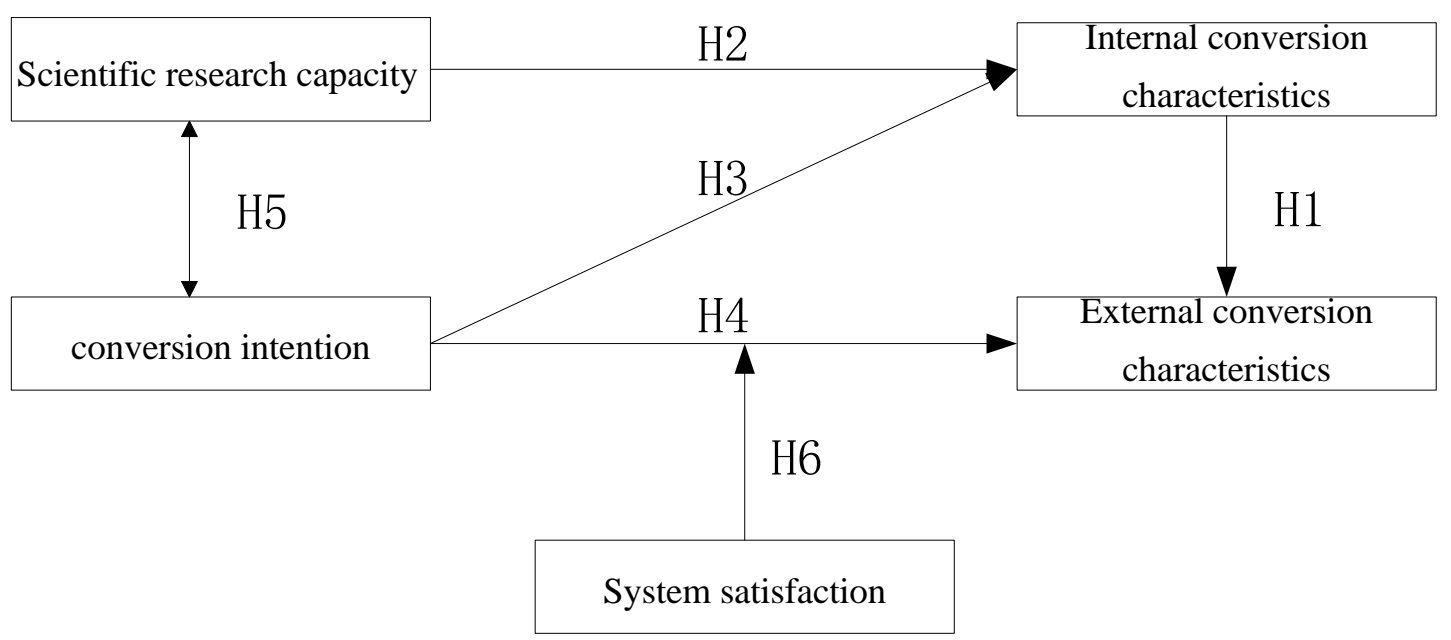

Fig. 1 Theoretical Model for the Internal Influencing Mechanism of Patent conversion

\section{B. Questionnaire Design}

In combination with theoretical model and expert interview opinions, design questionnaire and adopt Likert Level-5 scale. The meaning of various variables is as shown in Table I. 
TABLE I VARIABLE TABLE FOR Structural EQUATION MODEL

\begin{tabular}{|c|c|c|}
\hline Latent Variable & Measured Variable & Measurement Index \\
\hline \multirow{3}{*}{$\begin{array}{l}\text { Scientific research } \\
\text { capacity }(\mathrm{SRC})\end{array}$} & A1 & National scientific research institutions possess a strong R\&D capacity \\
\hline & A2 & National scientific research institutions possess perfect infrastructure \\
\hline & A3 & National scientific research institutions input enough fund into $R \& D$ \\
\hline \multirow{3}{*}{$\begin{array}{l}\text { Conversion } \\
\text { intention }(\mathrm{CI})\end{array}$} & B1 & Patent holders possesses the awareness of patent technology conversion \\
\hline & $\mathrm{B} 2$ & $\begin{array}{c}\text { Patent holders is willing to actively search for the patent technology conversion } \\
\text { undertaker }\end{array}$ \\
\hline & B3 & Patent holders is willing to participate in patent conversion process \\
\hline \multirow{3}{*}{$\begin{array}{l}\text { Internal conversion } \\
\text { characteristics(ICC) }\end{array}$} & $\mathrm{C} 1$ & The patent technology can reflect the currently advanced technical level \\
\hline & $\mathrm{C} 2$ & The patent technology possesses high maturity \\
\hline & $\mathrm{C} 3$ & $\begin{array}{l}\text { Within a short time, the patent technology cannot be replaced by other patent } \\
\text { technologies and schemes }\end{array}$ \\
\hline \multirow{3}{*}{$\begin{array}{l}\text { External conversion } \\
\text { characteristics }(\mathrm{ECC})\end{array}$} & D1 & The patent technology has big expected market profits \\
\hline & D2 & $\begin{array}{l}\text { The patent technology have no competitors with strong strength in the target } \\
\text { market }\end{array}$ \\
\hline & D3 & The development prospect for the industry of the patent technology is good \\
\hline \multirow{5}{*}{$\begin{array}{l}\text { System } \\
\text { satisfaction(SS) }\end{array}$} & E1 & $\begin{array}{l}\text { The patent technology conversion profit distribution obtained by the patent } \\
\text { technology holder is reasonable }\end{array}$ \\
\hline & E2 & National scientific research institutions gives enough respect to the patent holders \\
\hline & E3 & $\begin{array}{c}\text { The patent technology conversion intellectual property right ownership system for } \\
\text { national scientific research institutions is perfect }\end{array}$ \\
\hline & E4 & $\begin{array}{c}\text { The patent technology conversion profit distribution system for national scientific } \\
\text { research institutions is perfect }\end{array}$ \\
\hline & E5 & $\begin{array}{c}\text { The patent technology conversion procedures for national scientific research } \\
\text { institutions is perfect }\end{array}$ \\
\hline \multicolumn{3}{|c|}{ 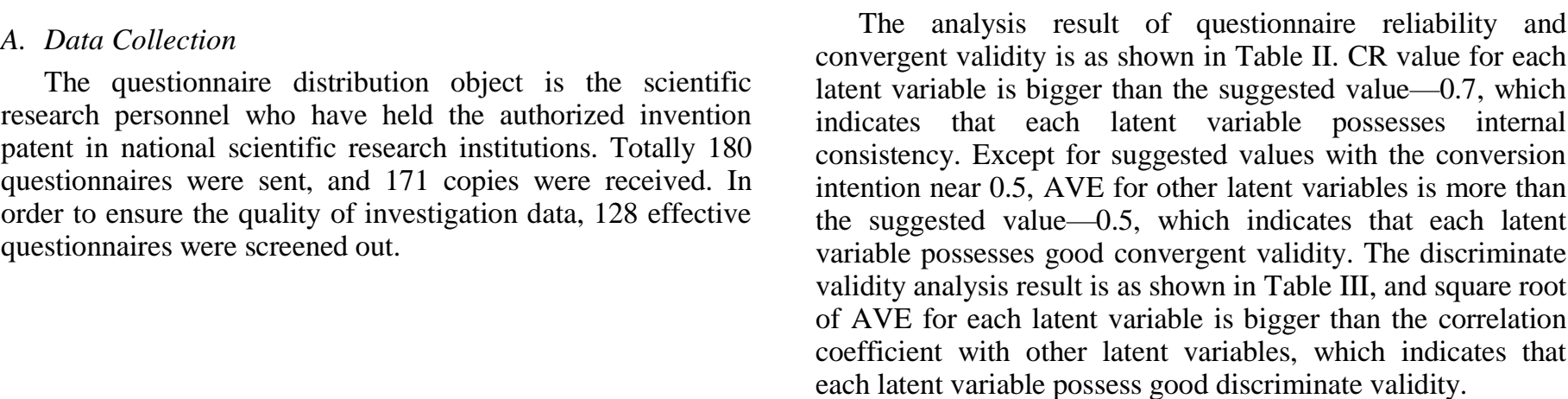 } \\
\hline
\end{tabular}


TABLE II RELIABILITY AND CONVERGENT VALIDITY ANALYSIS TABLE

\begin{tabular}{|c|c|c|c|c|c|c|c|c|c|}
\hline \multirow{2}{*}{ Latent Variable } & \multirow{2}{*}{ Measured Variable } & \multicolumn{4}{|c|}{ Sig. test of parameters } & \multirow{2}{*}{ Std. } & \multirow{2}{*}{$\begin{array}{c}\begin{array}{c}\text { Item } \\
\text { reliability }\end{array} \\
\text { SMC }\end{array}$} & \multirow{2}{*}{$\begin{array}{c}\text { Composite } \\
\text { Reliability } \\
\text { CR }\end{array}$} & \multirow{2}{*}{$\begin{array}{c}\begin{array}{c}\text { Convergent } \\
\text { Validity }\end{array} \\
\text { AVE }\end{array}$} \\
\hline & & Unstd. & S.E. & $\mathbf{Z}$ & $\mathbf{P}$ & & & & \\
\hline \multirow{3}{*}{ Scientific research capacity } & A1 & 1.000 & & & & 0.908 & 0.824 & \multirow{3}{*}{0.769} & \multirow{3}{*}{0.536} \\
\hline & A2 & 0.737 & 0.135 & 5.446 & $* * *$ & 0.685 & 0.469 & & \\
\hline & A3 & 0.673 & 0.135 & 4.986 & $* * *$ & 0.561 & 0.315 & & \\
\hline \multirow{3}{*}{ Conversion intention } & B1 & 1.000 & & & & 0.613 & 0.376 & \multirow{3}{*}{0.716} & \multirow{3}{*}{0.462} \\
\hline & $\mathrm{B} 2$ & 1.466 & 0.326 & 4.49 & $* * *$ & 0.818 & 0.669 & & \\
\hline & B3 & 0.865 & 0.178 & 4.87 & $* * *$ & 0.585 & 0.342 & & \\
\hline \multirow{3}{*}{$\begin{array}{l}\text { Internal conversion } \\
\text { characteristics }\end{array}$} & $\mathrm{C} 1$ & 1.000 & & & & 0.694 & 0.482 & \multirow{3}{*}{0.771} & \multirow{3}{*}{0.530} \\
\hline & $\mathrm{C} 2$ & 1.078 & 0.177 & 6.085 & $* * *$ & 0.691 & 0.477 & & \\
\hline & $\mathrm{C} 3$ & 1.297 & 0.214 & 6.051 & $* * *$ & 0.795 & 0.632 & & \\
\hline \multirow{3}{*}{$\begin{array}{l}\text { External conversion } \\
\text { characteristics }\end{array}$} & D1 & 1.000 & & & & 0.951 & 0.904 & \multirow{3}{*}{0.813} & \multirow{3}{*}{0.600} \\
\hline & D2 & 0.736 & 0.107 & 6.889 & $* * *$ & 0.74 & 0.548 & & \\
\hline & D3 & 0.528 & 0.089 & 5.93 & $* * *$ & 0.59 & 0.348 & & \\
\hline
\end{tabular}

TABLE III DISCRIMINATE VALIDITY ANALYSIS TABLE

\begin{tabular}{|c|c|c|c|c|c|}
\hline \multirow{2}{*}{ Latent Variable } & $\begin{array}{c}\text { Convergent } \\
\text { Validity }\end{array}$ & \multicolumn{4}{|c|}{ Discriminate Validity } \\
\cline { 2 - 6 } & $\mathbf{A V E}$ & $\begin{array}{c}\text { External conversion } \\
\text { characteristics }\end{array}$ & $\begin{array}{c}\text { Internal conversion } \\
\text { characteristics }\end{array}$ & $\begin{array}{c}\text { Conversion } \\
\text { intention }\end{array}$ & $\begin{array}{c}\text { Scientific } \\
\text { research capacity }\end{array}$ \\
\hline $\begin{array}{c}\text { External conversion } \\
\text { characteristics }\end{array}$ & 0.600 & $\mathbf{0 . 7 7 5}$ & & & \\
\hline $\begin{array}{c}\text { Internal conversion } \\
\text { characteristics }\end{array}$ & 0.530 & 0.443 & $\mathbf{0 . 7 2 8}$ & & \\
\hline Conversion intention & 0.462 & 0.404 & 0.599 & $\mathbf{0 . 6 8 0}$ & \\
\hline $\begin{array}{c}\text { Scientific research } \\
\text { capacity }\end{array}$ & 0.536 & 0.275 & 0.509 & 0.381 & $\mathbf{0 . 7 3 2}$ \\
\hline
\end{tabular}

Note: Square root of AVE in bold on diagonals, off diagonals are Pearson correlation of constructs

\section{Modeling}

The indexes of the model fit are as shown in Table IV, and it is relatively ideal, so it is applicable to utilize the estimated parameter of such model to test the assumption relations of various influencing factors, which are as shown in Figure 2. 
TABLE IV MODEL FIT TABLE

\begin{tabular}{|c|c|c|c|}
\hline $\begin{array}{c}\text { Statistical Test } \\
\text { Amount }\end{array}$ & Index Standard & Test Result & Model Fit Judgment \\
\hline CMIN & The smaller, the better & 63.298 & Ideal \\
\hline DF & The bigger, the better & 49 & Ideal \\
\hline CMIN/DF & $1-3$ & 0.932 & Ideal \\
\hline GFI & $>0.9$ is the ideal value, $>0.8$ is acceptable & 0.892 & Acceptable \\
\hline AGFI & $>0.9$ is the ideal value, $>0.8$ is acceptable & 0.960 & Ideal \\
\hline TLI(NNFI) & $>0.9$ is the ideal value, $>0.8$ is acceptable \\
\hline CFI & $>0.9$ is the ideal value, $>0.8$ is acceptable & 0.970 & Ideal \\
\hline RMSEA & $<0.05$ is the ideal value, $<0.08$ is \\
acceptable & 0.048 & \\
\hline
\end{tabular}

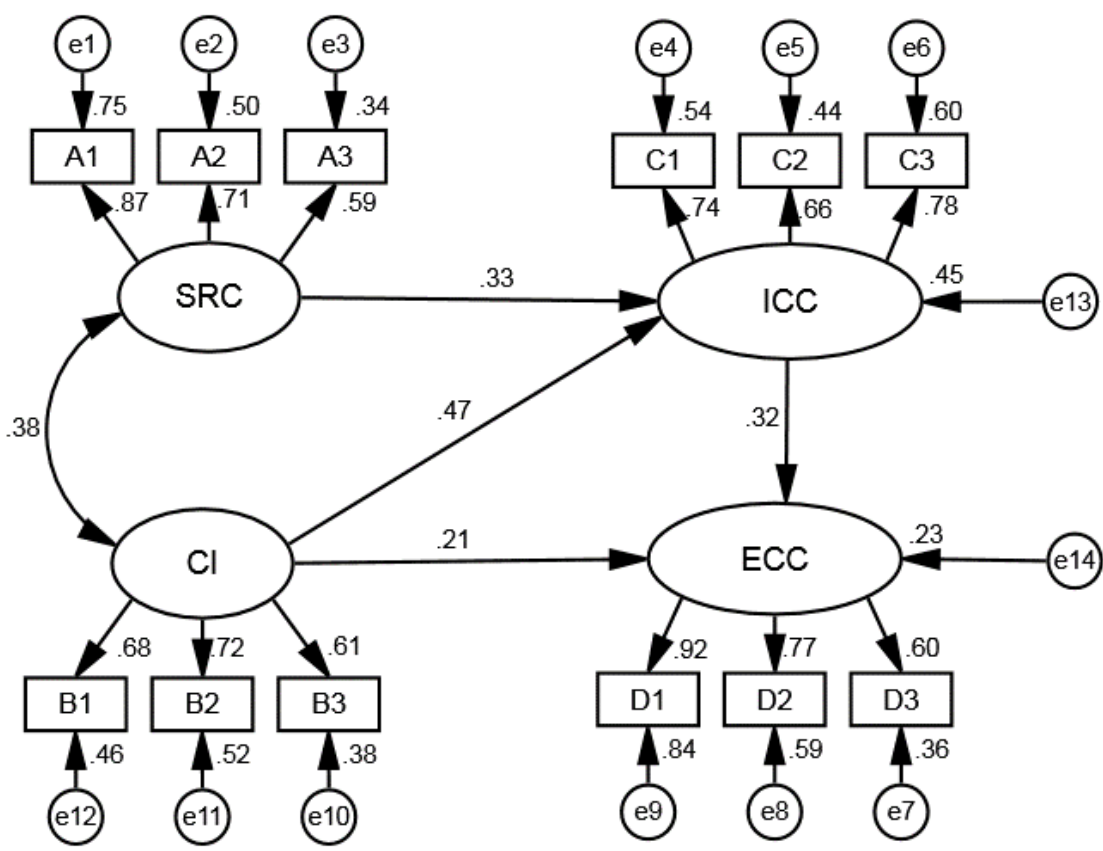

Fig. 2 Standardized Route Path Coefficient of Structural Equation Model

\section{Model Hypothesis Test}

Basis on Figure 2, the relation of four latent variables, including scientific research capacity, conversion intention, internal conversion characteristics, and external conversion characteristics is discussed, as shown in Table V: 
TABLE V LATENT VARIABLE RELATION TABLE

\begin{tabular}{|c|c|c|c|c|c|}
\hline \multirow{2}{*}{$\begin{array}{c}\text { Variable Relations } \\
\text { Non-standardized Estimated Parameters }\end{array}$} & $\begin{array}{c}\text { Standardized Estimated } \\
\text { Parameters }\end{array}$ \\
\cline { 2 - 5 } & $\begin{array}{c}\text { Path } \\
\text { Coefficient }\end{array}$ & SE & Z & P & Path Coefficient \\
\hline $\begin{array}{c}\text { External conversion } \\
\text { characteristics<---internal conversion } \\
\text { characteristics }\end{array}$ & 0.55 & 0.244 & 2.253 & 0.024 & 0.322 \\
\hline $\begin{array}{c}\text { Internal conversion } \\
\text { characteristics<---scientific research } \\
\text { capacity }\end{array}$ & 0.232 & 0.081 & 2.865 & 0.004 & 0.331 \\
\hline $\begin{array}{c}\text { Internal conversion } \\
\text { characteristics<---conversion intention }\end{array}$ & 0.41 & 0.115 & 3.553 & $* * *$ & 0.472 \\
\hline $\begin{array}{c}\text { External Conversion } \\
\text { characteristics<---conversion intention }\end{array}$ & 0.316 & 0.217 & 1.455 & 0.146 & 0.213 \\
\hline $\begin{array}{c}\text { Scientific research capacity<-->conversion } \\
\text { intention }\end{array}$ & 0.191 & 0.064 & 2.987 & 0.003 & 0.382 \\
\hline
\end{tabular}

(1) The non-standardized estimation between internal conversion characteristics and external conversion characteristics can meet $\mathrm{z}$-value $>1.96$, and $\mathrm{p}$-value $<0.05$, with significance; the standardized path coefficient is 0.322 , which indicates that internal conversion characteristics can exert certain degree of positive promotion effect on the external conversion characteristics, and Assumption H1 can be verified.

In a similar way, it can be known that:

(2)Scientific research capacity can exert a positive promotion effect on internal conversion characteristics, and Assumption $\mathrm{H} 2$ can be verified; in combination with Assumption $\mathrm{H} 1$, it can be seen that the scientific research capacity can indirectly influence external conversion characteristics through internal conversion characteristics.

(3) Conversion intention can exert a positive promotion effect on internal conversion characteristics, and Assumption $\mathrm{H} 3$ can be verified. In combination with the standardized path coefficient, it can be seen that, the positive influence effect of conversion intention on internal conversion characteristics is bigger than the positive influence effect of scientific research capacity on internal conversion characteristics.

(4) The non-standardized estimated z-value between conversion intention and external conversion characteristics is less than 1.96, and p-value is bigger than 0.05, without significance, and Assumption $\mathrm{H} 4$ cannot be verified. In combination with assumption $\mathrm{H} 1$ and $\mathrm{H} 3$, it can be seen that conversion intention can indirectly influence external conversion characteristics through internal conversion characteristics.

Bootstrap method (sampling for 5,000 times[10]) is adopted to further verify the significance of mediating effect, and the analysis result is as shown in Table VI, and the 95\% confidence interval for the indirect effect of scientific research capacity on external conversion characteristics excludes 0 , and p-value is less than 0.05 , with significance, so internal conversion characteristics of patent can exert fully mediating effect between conversion intention and external conversion characteristics, 
TABLE VI MEdiating VARiable Report TABLE

\begin{tabular}{|c|c|c|c|c|c|}
\hline \multirow{2}{*}{ Variable Relations } & \multirow{2}{*}{$\begin{array}{c}\text { Point } \\
\text { Estimation } \\
\text { Value }\end{array}$} & \multirow{2}{*}{ SE } & \multicolumn{3}{|c|}{$\begin{array}{c}\text { Bootstrap verification (Bias-Corrected 95\% } \\
\text { Confidence Interval) }\end{array}$} \\
\hline & & & Lower & Upper & $\mathbf{P}$ \\
\hline $\begin{array}{c}\text { Indirect effect: } \\
\text { external conversion } \\
\text { characteristics<---conversion } \\
\text { intention }\end{array}$ & 0.225 & 0.139 & 0.046 & 0.614 & 0.017 \\
\hline $\begin{array}{c}\text { Direct effect: } \\
\text { external conversion } \\
\text { characteristics<---conversion } \\
\text { intention }\end{array}$ & 0.316 & 0.266 & -0.176 & 0.868 & 0.183 \\
\hline $\begin{array}{c}\text { Total effect: } \\
\text { external conversion } \\
\text { characteristics<---conversion } \\
\text { intention }\end{array}$ & 0.542 & 0.212 & 0.195 & 1.057 & 0.003 \\
\hline $\begin{array}{l}\text { (5) Scientific research capa } \\
\text { ention can exert bi-directiona } \\
\text { sumption H5 can be verified. } \\
\text { Regulated Variable Hypothesis } \\
\text { Take Median } 15 \text { as the bounc } \\
\text { mparing the result of two gro }\end{array}$ & $\begin{array}{l}\text { and the } c \\
\text { lotion func }\end{array}$ & & $\begin{array}{l}\text { ering the } h \\
\text { r the system } \\
\text { del. As can } \\
\text { tricted mod } \\
-0.08 \text {, other } \\
\text { are relativel } \\
\text { luct regulati }\end{array}$ & $\begin{array}{l}\text { N systen } \\
\mathrm{n} \text { can exe } \\
\mathrm{m} \text { Table } \\
\text { lose to th } \\
\text { unrestric } \\
\text { it is acce } \\
\text { st. }\end{array}$ & $\begin{array}{l}\text { tions, } \\
\text { lating } \\
\text { pt for } \\
\text { able st } \\
1 \text { and } r \\
\text { use th }\end{array}$ \\
\hline
\end{tabular}

TABLE VII ADJUSTING Model FIT INDEX Report TABLE

\begin{tabular}{|c|c|c|c|c|}
\hline $\begin{array}{c}\text { Statistical Test } \\
\text { Amount }\end{array}$ & Index Standard & $\begin{array}{c}\text { Unrestricted } \\
\text { Model }\end{array}$ & $\begin{array}{c}\text { Restricted } \\
\text { Model }\end{array}$ & $\begin{array}{c}\text { Model Fit } \\
\text { Judgment }\end{array}$ \\
\hline CMIN & The smaller, the better & 122.295 & 133.623 & Ideal \\
\hline DF & The bigger, the better & 98 & 102 & Ideal \\
\hline CMIN/DF: & $1-3$ & 1.248 & 0.864 & Acceptable \\
\hline GFI & $>0.9$ is the ideal value, $>0.8$ is acceptable & 0.875 & 0.792 & Acceptable \\
\hline AGFI & $>0.9$ is the ideal value, $>0.8$ is acceptable & 0.801 & 0.900 & Ideal \\
\hline TLI(NNFI) & $>0.9$ is the ideal value, $>0.8$ is acceptable & 0.920 & 0.922 & Ideal \\
\hline CFI & $>0.9$ is the ideal value, $>0.8$ is acceptable & 0.940 & 0.050 & Ideal \\
\hline RMSEA & $<0.05$ is the ideal value, $<0.08$ is acceptable & 0.044 & & \\
\hline
\end{tabular}

As can be seen from Table VIII that, after restricting the path coefficient for various variables of the model as equal, the variation in the chi-square value of restricted model is obvious, so it can be judged that, the system satisfaction can exert an obvious regulation effect on the path relations of various latent variables, and Assumption H6 can be verified. 
TABLE VIII COMPARISON OF UNRESTRICTED MODEL AND RESTRICTED MODEL

\begin{tabular}{|c|c|c|c|c|c|c|c|}
\hline Name & DF & CMIN & P & NFIDelta-1 & IFIDelta-2 & RFIrho-1 & TLIrho2 \\
\hline Restricted model & 4 & 11.328 & 0.023 & 0.021 & 0.026 & 0.015 & 0.02 \\
\hline
\end{tabular}

\section{CONCLUSION AND SUGGESTIONS}

(1) The scientific research capacity of national scientific research institutions can exert an indirect positive promotion function on external conversion characteristics through the internal conversion characteristics of patent. In order to improve the scientific research capacity of national scientific research institutions, national scientific research institutions should establish clear development objective, effectively transfer and configure resources, reinforce technology and talent reserves, gradually perfect scientific research matching facilities, enhance the input strength of R\&D fund, implement comprehensive budget management, and ensure the constantly effective promotion of R\&D innovation capacity.

(2) The conversion intention of scientific research personnel can exert an indirect positive promotion function on external conversion characteristics through the internal conversion characteristics of patent. In order to improve the conversion intention of scientific research personnel, national scientific research institutions should adjust the existing performance evaluation system, and include the patent implementation and application conditions into the personal evaluation index and project acceptance standard; meanwhile, implement project relevance system; the patent implementation and application conditions for projects of the earlier period will be regarded as the reference for the follow-up task application, guide the scientific research personnel to start from the market, select a topic and set up the project, encourage scientific research personnel to actively participate in the conversion process, and pay attention to the production demand of enterprises and actively pursuit conversion undertaker.

(3) During the formation period, the patent conversion characteristics have been confirmed, and it is the basis deciding whether the follow-up commercialization and industrialization period can be successfully conducted. As the national scientific research institutions, it is requested to combine the current actual conditions, improve scientific research capacity and conversion intention, which can be good for improving the internal characteristics of patent conversion, and then facilitate the promotion of external conversion characteristics of patent. Compared with the scientific research capacity, the influence of conversion intention on the external characteristics of patent conversion is bigger. The national scientific research institutions should emphasize on promoting the conversion intention of scientific research personnel, and improve the external characteristics of patent conversion to a large extent.

(4) System satisfaction has a moderating effect on the path relation of scientific research capacity, conversion intention, international conversion characteristics, and external conversion characteristics. Under the current social environment of China, the moderating function of system satisfaction isn't fully played. The national scientific research institutions should further optimize the intellectual property right and conversion profit distribution system, perfect the patent conversion procedures, reinforce the material and spiritual motivations of scientific research personnel, and help patent conversion realize a bigger market profit and industrial development prospect.

\section{REFERENCES}

[1] State Intellectual Property Office of The P.R.C. 2016 Chinese Patent Data Investigation Report [EB/OL]. (2017-06-30). http://www.sipo.gov.cn

/zscqgz/2017/201706/t20170630_1312349.html.

[2] Zeng Li and Luo Xiaohan. Analysis and Thoughts about Patent conversion and Relevant Basic Concepts [J]. Scientific \&Technology Progress and Policy, 2015, 32 (12): 109-113.

[3] Wang Ruimin, Teng Qing, and Lu Feifei. Analysis on the Factors Influencing Patent conversion in Colleges and the Countermeasures Research [J]. Science Research Management, 2013, 34 (3): 137-144.

[4] Chen Zhifang, Shi Jinjie and Duan Jiangtao. Research about the Influencing Factors for the Implementation of Patent conversion and the Evaluation System Based on AHP [J].Journal of Modern Information, 2015, 35 (11): 49-53.

[5] Gong Binggang. Patent Technology Conversion Performance Evaluation for Scientific Research Institutions Based on Fuzzy Neural Network [D]. Beijing: Beijing Jiaotong University, 2014.

[6] Zhang Ping, Huang Xiantao, and Wang Chenchen. Patent Technology Conversion Evaluation system Construction and Application [J]. Chinese University Technology Transfer, 2011, (11): 62-64.

[7] Wang Jian and Li Yanping. Analysis on the Valid Mode of Patent conversion in Colleges Based on Patent Right Transfer [J]. Forum on Science and Technology in China, 2016, (04): 70-75.

[8] Li Chang, Tang Heng, Jin Yucheng et al. Patent conversion Mode Selection Influencing Mechanism and Evolution Model in Colleges [J]. Forum on Science and Technology in China, 2016, (04): 76-82.

[9] Li Lingjuan, Huo Guoqing, Zeng Mingbin et al. Review about Scientific Research Achievement Conversion Policy Based on the Value Chain [J] Scientific Management Research, 2014, 32 (1): 10-14.

[10] Andrew F. Hayes. Beyond Baron and Kenny: Statistical Mediation Analysis in the New Millennium [J]. Communication Monographs, 2009, 76 (4): 408-420. 